\title{
Editorial
}

\section{Hemorheology and musical arts}

\author{
Friedrich Jung, Sandro Forconi and Michel R. Boisseau
}

In this issue of Clinical Hemorheology and Microcirculation Norbert Nemeth publishes a well-written analysis of the often strong attraction to arts, and especially to musical arts, of people of medical vocation and possible reasons therefore [1].

The quest to comprehend the human body and soul, to detect our own vital signs and signs of psychosomatic processes materializes especially in the music, the art with the most complex effects on human sensory reception. Some vital signs like appearance, dynamic changes and the seemingly endless movement of blood and blood circulation are used by artists as expression of life and death. The author beautifully describes the analogy between progress and flow of music with the running of blood, the speeding or slowing tempo and even the fatal arrest of circulation. He reminds A.L. Copley who linked scientific work and hemorheology with arts, nicely demonstrated in his design of the Fahraeus Medal [2].

A description of "music in medicine" with the known and scientifically approved effects on biological parameters of circulation and on the nervous system is given as well as a description of "medicine in music".

In a few divisions, physiological and pathological phenomena of circulation and blood, diseases or care taking medical persons are portrayed describing circulation, stream, rhythm, bleeding, and appearance of blood in the more or less brilliant compositions of musical arts. It may be unusual, but we decided that this manuscript should published in this journal because it is worthwhile considering the authors attitude to become one with an artwork can mean a momentary liberation for the mind grown wary of everyday limitations, duties, responsibilities, decisions and questions, contributing to a more balanced life and aiding medical activity.

\section{References}

[1] N. Nemeth, Blood stream in the art: Thoughts on music and hemorheology, Clin. Hemorheol. Microcirc. 41 (2009), 221227 (this issue).

[2] S. Forconi, Fahreus Awardee - Professor Michel Rene Boisseau, MD, Clin. Hemorheol. Microcirc. 35 (2006), 7-9. 